\title{
EL NACIONAL-VICTIMISMO: ENTRE EL DERECHO DE RESISTENCIA Y EL DERECHO DE AUTODETERMINACIÓN. ¿UN NUEVO TIPO DE RACISMO?
}

\section{THE NATIONAL-VICTIMISM: BETWEEN THE RIGHT OF RESISTANCE AND THE RIGHT OF SELF-DETERMINATION. A NEW TYPE OF RACISM?}

\author{
Pedro Francisco Gago Guerrero \\ Profesor \\ Universidad Complutense de Madrid \\ pedrogago@trs.ucm.es \\ España, Madrid
}

\section{SUMARIO}

- Introducción.

- Qué es el nacional-victimismo.

- El racismo del nacional-victimismo.

- La estrategia del victimista del nacionalismo.

- El gobernante como doble agente del nacional-victimismo.

- La utilización del derecho de autodeterminación por el nacionalvictimismo.

- Cuando el sistema político es incapaz de controlar al nacional-victimismo.

- Conclusiones.

\section{RESUMEN}

El nacional-victimismo se sustenta en una ideología de racismo profiláctico que habrá de crear una estrategia política con el fin no solo de independizar un territorio de la nación del que forma parte, expropiándolo sin causa justa, sino para formar un estado despótico de seres racialmente superiores. Al ser una adaptación del racismo a las nuevas realidades, utilizan la defensa de los derechos subjetivos y el derecho de los pueblos para conseguir dominar y transformar a los ciudadanos que no han evolucionado o han tenido una tara genética. Motivo por el que el nacional-victimismo será una corriente más que rechaza la dignidad e igualdad humana. Su estrategia para conseguir sus objetivos consistirá en utilizar el derecho de autodeterminación, avalado por el derecho de resistencia, para una vez conseguir los fines perseguidos, imponer un derecho de subordinación, eliminando la igualdad jurídica y creando un nuevo Lebensraum.

\begin{abstract}
National-victimism is based on an ideology of prophylactic racism that will have to create a political strategy in order not only to make independent a territory of the nation of which it forms part, expropriating it without just cause, but also to form a despotic state of racially superior beings. Being an adaptation of racism to the new realities, they use the defense of subjective rights and the right of peoples to dominate and transform citizens who have not evolved or have had a genetic tare. That is why national-victimism will be one more current that rejects human dignity and equality. Its strategy to achieve its objectives will consist of using the right of self-determination, guaranteed by the right of resistance, to once achieved the goals pursued, impose a right of subordination, eliminating legal equality and creating a new Lebensraum.
\end{abstract}

\section{PALABRAS CLAVE}

Nacional-victimismo; racismo; derecho de resistencia; entreguismo.

\section{KEYWORDS}

National-victimism; racism; right of resistance; appeasement. 


\section{INTRODUCCIÓN}

Buena parte de Europa y algunos países de la civilización occidental parecen encontrarse en una era de pensamiento y mentalidad débiles, ajenos a la importancia que supone reducir la fuerza por haber asumido un voluntarismo pacifista, que, entre otros objetivos, tiene el propósito de eliminar la enemistad entre los Estados, para sustituirlo por las relaciones de comprensión y solidaridad de acuerdo a un ideal universalista, presumible sustituto de la política internacional. Domina la corrección política producto de la modernidad basado en la igualdad, la libertad, la justicia social, la no discriminación, la restitución de lo robado por las anteriores generaciones, que se podría remontar a cientos de años, la protección a las minorías a las que otorgará más de lo necesario, porque al parecer son la expresión de una grandeza estructural y superioridad moral, etc. Igualmente se pone buen cuidado en respetar a quienes tengan como objetivo alcanzar el cielo terráqueo, elevado a categoría jurídica. No obstante, en el fondo, dominan los principios políticos que caracterizan el sistema internacional.

En este trabajo se analizará el nacionalvictimismo utilizando las categorías que hasta ahora han determinado la acción política, partiendo de un desarrollo dialéctico que permitirá clarificar la expresión general del movimiento. Siendo político su principal objetivo, independizarse de la Nación-Estado a la que pertenece, será imprescindible conocer sus principales rasgos. Que, por cierto, pueden afectar a cualquier parte de los Estados del sistema internacional. Incluidos aquellos que no tengan problemas de convivencia y estén muy bien ensamblados.

Aunque no hay dudas de lo positivo que sería para una sociedad extender la protección jurídica de las personas mediante la ampliación de los derechos, cabría sostener que también podrían provocar previsibles efectos negativos. Por ejemplo, si bien el nacional-victimismo quiere conseguir unos supuestos derechos para una parte de un colectivo, a la vez niega los mismos derechos a los restantes ciudadanos.

Su aportación consistirá en crear un nuevo estado con un ordenamiento jurídico basado en unos principios que habrán de ser diferentes a los del Estado de que forman parte como ciudadanos. El movimiento se opondrá a la actual tendencia del humanismo hacia el cosmopolitismo y el rechazo real a los derechos humanos. La explicación se encontrará en la voluntad del nacional-victimismo de establecer su superioridad racial sobre el resto de los habitantes de la nación.

En el trabajo se diferenciará entre ser víctima ${ }^{1}$ y hacerse la víctima. Se califica como víctima a una persona sobre la que se ha ejercido la fuerza, violando alguno de sus derechos, sean fundamentales o no. Por el contrario, el victimista hará creer que sufre una coerción permanente y una indefensión jurídica ${ }^{2}$. Aparece el nacional-victimismo cuando muchos individuos se imaginan o se inventan una represión, con el objetivo de apropiarse del poder de todas las instituciones. Una vez conseguido, buscará otros objetivos políticos en consonancia con sus anteriores resultados. Este tipo de nacionalismo, compondrá una escenografía teatral perteneciente al género moralista falsario, consistente en hacerse pasar por un colectivo sufriente a causa de la permanente represión llevada a cabo por un Estado castigador innecesario, sobre los sujetos más sobresalientes de la sociedad todos los nacional-victimistas-.

\section{QUÉ ES EL NACIONAL-VICTIMISMO}

El movimiento nacionalista independentista racista postmoderno ha de elegir entre dos principales opciones: la violencia terrorista, o la de ejercer una presión sin aparente violencia desde las instituciones del propio Estado y con la fuerza de un amplio movimiento social.

Entre las características del nacionalvictimismo cabe destacar las siguientes: $1^{\circ}$. Esgrime una fuerza de voluntad impositiva y excluyente. $2^{\text {o }}$ Tratará de imponerse al resto de la ciudadanía con falsas actitudes identitarias. $3^{\circ}$. Es una más de las adaptaciones de la cultura de la queja ${ }^{3}$. $4^{\circ}$. Intentará hacer creer que los derechos de los habitantes del territorio son violados permanentemente y así conseguir el apoyo natural que suelen producir

1 Vid. Daniele Giglioli. Crítica de la víctima. Barcelona, Herder, 2017.

2 La victima siempre es una persona, no un colectivo, puesto que no todos los que integran una sociedad son reprimidos.

3 Dice sobre ello Rafael Núñez (2018), "determinados grupos de presión saben que la queja puede ser un eficaz instrumento de movilización para alcanzar sus propios objetivos de poder" (Párrafo 8). 
¿Un nuevo tipo de racismo?

The national-victimism: between the right of resistance and the right of self-determination.

A new type of racism?

las víctimas. $5^{\circ}$. Fabulará una situación de general represión y latrocinio que causa el Estado del que depende. $6^{\circ}$. Se asienta en una estrategia política que apoyará a su vez en una moralina extraída del derecho de autodeterminación, producto de un abstracto bien humanitario que tiene el deber de liberar a la población sojuzgada contra un enemigo que es la encarnación e institucionalización del mal absoluto. $7^{\circ}$ Instrumentalizará la moral convirtiéndola en moralina, una burda base de real inmoralidad tiránica ${ }^{4}$, que pasará a formar parte de lo impolítico. $8^{\circ}$. Al hacer de la mentira una justificación para cualquier tipo de acción, creará nuevos códigos de una ética de uso alternativo a su conveniencia, preferiblemente basados en una constante degradación de la moral con el fin de viciar cualquier relación social. $9^{\circ}$. Su actividad pacifista consistirá en desobedecer al Estado y a su ordenamiento jurídico - la voluntad ha de estar por encima de las leyes-. $10^{\circ}$. Al formar parte de una subcultura revolucionaria, con un fondo caótico y destructivo, justificará la desobediencia civil y política. $11^{\circ}$. Como pseudo-pensamiento sentimental e irracional, emotivo y maniqueo, se manifiestará como una forma inferior de contenido político (Hegel), sustentando en una banalidad ilusoria, propia de una sociedad adolescente (Alain Finkielkraut). 12 ${ }^{\circ}$. No se apoyará en la razón, sino en la visceralidad sentimental, constituida a partir de una estrategia asentada en un cinismo extremado, siendo su fin tan delusivo como los medios que justifica para llegar a su consecución. 13․ La formación y consolidación de la ficción tendrá que ocultar su historia anterior e inventarse un pretérito. $14^{\circ}$. Las oligarquías iniciadoras del movimiento buscarán conquistar el poder para repartirse los beneficios. En cuanto a la plebe victimista se conformará con algunos regalos en forma de empleos y subvenciones que costeará el erario público "tiránico" ${ }^{\circ}$ 15\%. Rechazarán los principios fundamentales del orden jurídico del que formarán parte. Quizá sus actos sean un tipo de delito que "podría ser útil para preparar directamente cambios sociales, anticipándose a la moral del futuro" (Falcón 2009, página 69). $16^{\circ}$. El nacionalvictimismo no sólo aprovechará la extendida mentalidad

\footnotetext{
4 Por ejemplo, adaptan a su conveniencia el derecho a la autodeterminación, haciéndose unos oprimidos colonizados.

5 Tiene relación con la idea de Lenin (1973) de que "el desarrollo de las grandes potencias capitalistas y el imperialismo hacen ilusorio el "derecho de autodeterminación" de los pequeños pueblos". (Página 47)
}

humanitaria para conseguir su principal objetivo político, sino que buscará una gran indemnización por los años de sufrimiento provocados por el que juzga como dominio colonial. $17^{\circ}$. Presentándose como oprimido, le permitirá actuar con muchas licencias y recibir ayudas de todo tipo, entre ellas las del internacionalismo colectivista. $18^{\circ}$. Hará creer que forman parte de un activo ejercicio progresista de la historia al pasar como un movimiento liberador de los explotados sometidos a la fuerza represiva de un Estado.

A estos rasgos se suman otros contenidos, muchos de los cuales dependerán del contexto en que se produzcan:

a) La voluntad del nacional-victimismo será independizarse del Estado al que pertenece, poniendo a disposición de este fin $^{6}$ todos los campos sociales y órdenes y utilizando unos medios que formarán parte de un extremado ejercicio cínico de la política. Nunca sus acciones podrán tener como objetivo liberarse de la opresión, dado que, si la hubiera, sería menor que para los restantes componentes de la sociedad. Por esta causa buscará una estrategia consistente en presionar pacíficamente al Estado, renunciando provisionalmente a la violencia.

b)La corriente victimista aparecerá y se desarrollará en un contexto de debilidad del Estado, siendo para el "oprimido" el momento propicio para aumentar su fuerza y liberarse de la "sujeción". También se aprovechará de la extensión de la mentalidad humanitaria y pacifista, tan extendida en los países desarrollados, cuyos militantes apoyarán cualquier movimiento que se invente una opresión, con un especial apoyo por los presuntos liberadores de la humanidad, y a cualquier tipo de tiranía que se autodenomina liberadora -la tiranía que apoya a otra potencial tiranía-. De modo que, en este contexto contradictorio, el nacional-victimismo al querer formar parte del universal-humanitarismo tendrá muchas posibilidades de imponer sus conceptos y categorías. Es decir, que los opresores se conviertan en oprimidos, los explotadores pasen por explotados y los generadores de mentiras interrumpidas ejemplos de las verdades históricas.

6 Vid. Ángel Bizcarrondo, El triunfo del victimismo. El Español, 9 de mayo de 2018 
c) Puesto que el objetivo del nacionalvictimismo será desprenderse de la matriz a la que debe su identidad, carecerá de legitimidad, y tendrá que recurrir a fundamentar sus acciones convirtiendo el proceso político sentimental en un derecho humano colectivo, basado en un fundamento sentimental y una moral adaptable a las circunstancias ${ }^{7}$. Formará parte de un proceso político basado en la ideología de lo políticamente correcto, por lo que se le evaluará en la práctica por el éxito o el fracaso de su empresa, sin considerar si sus acciones son justas y gravemente destructivas.

d)El nacional-victimismo es un movimiento ecléctico mezcla de cratología y de ideologismo, destacando la fuerza que impulsan las ideologías internacionalistas ${ }^{8}$, aunque apenas incorporen elementos originales. Esta mezcolanza nacionalinternacionalista de puro oportunismo político, se aparta de los ideales basados en la unidad humana. Al carecer de fundamentos legales, sus portadores intentarán que la política y el derecho se adapten a su amoralinmoralidad de beneficio propio-los intereses de la moralina situacionista particular-. Por el mismo motivo el nacional-victimismo rechazará el ordenamiento jurídico del Estado del que forman parte justificando la creación de su propio derecho. Por tanto, intentará convertir sus actos en creaciones legislativas y en modelos de moralidad, en realidad una amoral-inmoralidad, para componer un nuevo sentido de la justicia, plasmado en un nuevo orden jurídico basado en un supuesto derecho nacionalcolectivista.

e) Para eliminar la represión a la que dice verse sometido, el nacional-victimismo se presentará como un pueblo en movimiento formando una unidad intemporal de conveniencia y coexistencia, buscando apropiarse tanto del territorio como de la conciencia social. Puesto que el movimiento nunca conseguiría el apoyo unánime de los ciudadanos, justificará el empleo de cualesquiera acciones destructivas y de todas las argucias, mecanismos y tácticas para conseguir una acción unitaria sin

7 En los momentos actuales dominados por el relativismo apenas importa que su pretensión sea inmoral.

8 El colectivismo tiene una tendencia a apoyar cualquier nacionalismo de otra unidad política. En gran medida los antisistema colectivistas -contradictio in terminis- son estalinistas, ya que preconizan la construcción del socialismo en un solo país. interrupciones. Utilizará a su conveniencia los términos pueblo, sociedad, humanidad, etc. ${ }^{9}$, adaptándolos a la situación, al mismo tiempo que rechazará los fundamentos de los diferentes órdenes del Estado "opresor".

f) Aparte de participar del movimiento de masas, el nacional-victimismo se compondrá, simplificando, de fanáticos ${ }^{10}$ puros y de falsos fanáticos. Los primeros tendrán una mentalidad predispuesta a creer en los mayores disparates, habiéndose construido ellos mismos una personalidad bipolar dominada por el empeño de seguir a la mentira y defenderla hasta la exageración, añadiéndola y sustentándose con dos ingredientes decisivos: el odio y el resentimiento ${ }^{11}$, nacidos, por lo general, de las frustraciones individuales. Los segundos, los falsos fanáticos, sabrán muy bien cuando detenerse y utilizarán todas las artimañas para beneficiarse del movimiento y de quienes lo componen.

g) Una de las causas por las que los individuos apoyarán el victimismo en la llamada era del vacío (G. Lipovetsky, 1986), se debe a que una parte destacable de la sociedad carece de recursos vitales, siendo incapaces de realizar su personalidad, viviendo en un profundo relativismo y aceptando la hipocresía como principal modo de vida. Siendo estos individuos sentimentaloides, frustrados, carentes de nobleza y gregarios, apoyarán lo que pueda ser más negativo para los demás, optando por destruir al enemigo que ellos mismos han imaginado para justificar su tendencia al mal. Quizá tengan razón Bradley Campbell y Jason Manning (2018), sobre las consecuencias que provoca el paso de la cultura del honor a la cultura de la dignidad, a partir de la cual brotará un apéndice que es la cultura del victimismo colectivista, ciertamente como una degeneración utilitaria del principio de dignidad humana, que buscará con la mentira el apoyo de las sociedades -la indignidad del que lucha cínicamente por dotarse de aparente dignidad-.

9 Vid. Snjezana Kordic. Lengua y nacionalismo. Madrid. Euphancia Ediciones. 2014.

10 Vid. Sigmund Freud, Psicología de las masas y análisis del yo. El psicólogo austriaco deduce que de la multitud es fácil que surjan muchos fanáticos.

$11 \mathrm{El}$ victimismo, dice Antonio Escohotado (2003) "vive repartiendo papeles de culpabilidad e inocencia a diestro y siniestro, sin otro tribunal juzgador que el propio e irresponsable resentimiento" (Párrafo 6). 
¿Un nuevo tipo de racismo?

The national-victimism: between the right of resistance and the right of self-determination.

A new type of racism?

h) Al igual que el nacional-victimismo habrá de surgir en un Estado débil, nunca aparecerá en una sociedad bien conformada, sino en una situación de debilidad política y degradación moral. Contrariamente a lo que hacen creer sus partidarios no aparece por causa de la represión, sino de una interesada actitud individual de quienes no pueden vivir sin odiar a un gran grupo abstracto, canalizando las frustraciones que podrían derivar en una violencia extrema. Por eso los sentimientos negativos los dirigirá contra el que califica de enemigo, al tiempo que, en su existencia ordinaria, pero sobre todo enajenada, querrá sentirse superior sobre quien desprecia. El problema es que una vez que el odio ha inundado cada espíritu particular, dejará de tener conciencia sobre lo justo y eliminará de su vida la verdad y el bien.

i) El amorfo movimiento estará compuesto en lo más alto de la pirámide por descerebrados que hacen gala de su incultura, sin capacidad de liderazgo, aunque hayan ascendido en lo más alto de la jerarquía institucional. La mediocridad, acaso por la corrupción del régimen político, se elevará institucional y socialmente, haciendo creer a los ingenuos que pertenecerá a una categoría superior. En realidad, entre los líderes habrá muchos deformes psíquicos, aunque muy aclamados por su rebaño, que adquirirán cada vez más fuerza por la incapacidad del oponente. En mayor medida si coincide con otro gobernante de la "opresión" que tenga parecida deformidad.

j) Si el victimismo se basa en una inventada "represión" y en un proceso ininterrumpido de falsear la realidad, lógicamente no admitirá el Bien, ni siquiera en los detalles poco importantes. Lo moralmente bueno solo serviría para ser utilizado como engaño. Es decir, que intentará que la mentira pase por ser un bien utilitario (i). Deduciéndose entonces que el bien común será inaceptable. En cambio, el mal tiene todas las posibilidades de cuadrar en las acciones de la estrategia victimista.

k)Siendo sentimentalista en el fondo y en la forma, se dedicará a una labor de concienciación en la opinión pública internacional a fin de que considere ilegítima cualquier tipo de acción represiva contra su movimiento. Su éxito radicará en que se admita que el único derecho sea el del victimista, y que se niegue cualquier derecho a que el Estado opresor prosiga sus acciones contrarias a sus aspiraciones. Es decir, que sólo ellos podrán tener el uso y el disfrute de los derechos.

\section{EL RACISMO DEL NACIONAL- VICTIMISMO}

El nacional-victimismo formará parte de una corriente aparentemente pacifista y realmente racista, por convicción o conveniencia, adscribiéndose a la moralina política por transformar al oponente en enemigo diabólico. Un supremo mal con el que califica al Estado del que depende y las gentes que lo componen; esto es, seres inferiores -bestias con forma humana ${ }^{12}$ - que injustamente han constituido una Gran Institución a costa de someter por la fuerza a quienes son superiores moral y orgánicamente al resto de los componentes de la población. Forman parte, pues de una raza superior creadora de una cultura superior.

En realidad, en un Occidente probablemente decadente, el nacional-victimismo será una de las corrientes racistas más destructivas, como expresión de la política demonológica. En su banal falsedad, los nacional-victimistas apelarán a las personas sensibles amantes de los derechos para que puedan comprender que hay pocas cosas más crueles que sentirse reprimidos por seres a los que cataloga como infrahumanos. Una creencia que cualquier individuo menos dotado de inteligencia tomará por una prueba científica irrefutable.

La creencia del nacional-victimista de que sus facultades morales e intelectuales dependen de la raza (rassengebunden) y que su superioridad racial está basada en que su naturaleza está más evolucionada ${ }^{13}$, y que al poseer capacidades superiores conseguirá las mejores prestaciones psíquicas, sexuales, artísticas, etc. Esta superior constitución contrastaría con la escasa evolución, cuando no una involución, de otros organismos inferiores con apariencia humana, los represores, que utilizando

12 Esta manifestación sobre muchos millones de personas de quien se considera un ario, pretende superar intelectualmente a Houston Stewart Chamberlain, a JosephArthur Gobineau, Ernst Haeckel y a Alfred Rosemberg, como encarnación modelo de la purificación redentora de la raza superior.

13 Vid. Valentín Almirall y la frenología etnicista de Bartolomé Robert. Últimamente se podrá consultar la todavía obra incompleta del ario Quim Torra. 
diferentes artimañas de animales depredadores han logrado imponerse a los mejor dotados. $\mathrm{Se}$ infiere que el victimismo nacionalista recogiendo el evolucionismo racista, coincide en lo esencial con el nacionalsocialismo, aunque la abundancia de descerebrados en la actualidad ${ }^{14}$ posiblemente superará a los que apoyaron al III Reich, faltándoles su extraordinaria escenografía.

La creencia racial victimista suele tener una gran capacidad para captar adherentes entre la gente frustrada y resentida. Les hace creer que forman parte de una comunidad étnicamente superior ${ }^{15}$. Esta comunidad, elegida como un cuerpo especial por el cosmos o los astros, tendrá el efecto mágico de elevar a los individuos hacia la posición donde solo moran los que se imaginan poseer una alta inteligencia ${ }^{16}$, dándoles el derecho de renegar de la historia. De modo que sub specie aeternitatis, ya les será concedido por los dioses la superioridad perpetua -un imperio de mucho más de mil años-, y hasta creerán que podrán constituir una especie de Estado Moral guía para el resto de la humanidad subordinada.

Este es el principal motivo por el que los victimistas buscarán que impere la justicia, ya que consideran inadmisible que otros humanos con un ADN menos evolucionado, o con una tara genética ocurrida en la historia biológica, no se les permita demostrar sus elevadas capacidades y vivir de acuerdo a su condición. La única razón por la que han dominado los seres inferiores se debe a que han llegado a tener una fuerza represiva propia.

A partir de conquistar el Estado, previa rendición sin lucha por el gobernante, las instituciones y la parte del pueblo que les apoye, iniciará su correspondiente transformación en estatalización racial - ¿Una nueva adaptación de la sangre y la tierra (Blut und Boden)?-, por lo que cualquier rebelión o resistencia al poder, aunque sea pacífica, será reprimida. El nuevo estado estará legitimado por los certificados de $\mathrm{ADN}^{17}$ que formarán los individuos más evolucionados. A partir de entonces se empezará a consolidar la justicia eterna.

14 No hay que olvidar que al formar parte del postmodernismo una de sus principales caracteristicas es la estupidez. Vid. André Glucksmann, La estupidez. Ideologías del postmodernismo, Barcelona, Península, 1997.

15 Ya Guido von List sostuvo a principios del siglo XX, en 1904, que los arios tenian un origen divino.

16 La imbecilidad que se cree empingorotada sobre el pavés.

17 Una reconstrucción y adaptación de la insignia nazi Blutorden (Orla de la Sangre).
Muy probablemente los individuos que integran el victimismo no se caracterizarán por su valentía ${ }^{18}$, aunque la estrategia les obligará a ser constantes en la presión aparentemente pacífica sobre los cobardes "opresores", sin importarles que se conviertan en siervos si lograsen desprenderse del dominio de los seres humanos genéticamente atrasados. El racismo actual, victimista nihilista, se compondrá por una masa deforme y servil, ciegos de clarividencia y voluntariamente sometidos a las degeneradas oligarquías, aunque se autoproclaman superiores para ocultar su miserable realidad. Al ser el victimista un producto del encanallamiento individual, todos los "arios" ignorantes de lo que es la virtud formarán parte del movimiento. No deja de ser un recurso muy práctico para el nacionalvictimismo, de ínfima inteligencia cultural. En el fondo posiblemente habrá envidia al "opresor", porque si forma parte de una nación de amplia tradición, casi con seguridad no podrá aludir apenas a algún mérito histórico, salvo los que quiera inventarse, nacionalizando cualquier aportación destacable y convirtiendo a las grandes figuras en arios surgidos en el territorio que quiera independizarse ${ }^{19}$.

Al objeto de limpiar la sangre inficionada, muchos de los victimistas con un ADN retrasado, provenientes de la emigración, se querrán incorporar al movimiento para mejorar su genética mediante trasplantes miméticos de lo que considera sangre pura, abandonando su pertenencia a la etnia inferior. Siendo este racismo tan científico, ¿cómo no comprender que los victimistas no harán lo imposible por liberarse del dominio de los genéticamente inferiores?

Caben muchas dudas acerca de que si llegaran a conseguir sus objetivos, los "liberados", incluso siendo biológica e intelectualmente "superiores", no podrían construir una sociedad mínimamente justa al nacer de la mentira, de la superioridad étnica, del espacio vital en que debe vivir el victimista a fin de que no sean asfixiados por los animales humanos poco evolucionados. No les quedará más remedio

18 Un rasgo fundamental que deberá tener el político. Vid. H. Arendt. El ensayo de 1953 La gran tradición, en Pensar sin asideros. Ensayos de comprensión 1953-1975. Volumen II. Barcelona. Página Indómita, 2019, páginas 101 y ss. También, La condición humana. Barcelona. Paidós, 1996, en página 47.

19 Intentarán contrarrestar la falta de una historia relevante inventándose un pretérito cuando probablemente apenas han sido algo en la historia de la humanidad. 
¿Un nuevo tipo de racismo?

The national-victimism: between the right of resistance and the right of self-determination.

A new type of racism?

que violentar fuertemente a la sociedad, excluyendo a quienes no participan en el ágape falso estructural y reprimirlos fuertemente con el objeto de no dejar ninguna opción a que vuelvan a recuperar su posición.

\section{LA ESTRATEGIA VICTIMISTA DEL NACIONALISMO}

Puesto que el victimismo es una moralina (Nietzsche 1996) impolítica, que nunca aceptará la situación real, tendrá que establecer una estrategia general basada en una sucesión de tácticas pacíficas que responderán a intenciones aviesas.

La gran baza del victimismo será confeccionar una estrategia atípica en la historia, puesto que el poder, con excepción, y no siempre, en un régimen democrático, se conquista por la fuerza. Por ello pretenderá legitimar sus actos como un movimiento que buscará desprenderse de la sujeción, fundándose principalmente en un derecho a la liberación, que será el que respalde las acciones políticas. Es decir, que el nacionalvictimista se rebelaría contra el poder político y el ordenamiento sojuzgador, estando moral y políticamente obligados a desobedecer para acabar con el mal de la opresión.

La estrategia siempre estará conformada y dirigida por unas oligarquías conscientes de su interés espurio, y se verán acompañados en el viaje hacia el nunca jamás con los grupos y partidos, con diferentes fines, que, en principio, son opuestos al nacionalismo, caso de los grupos antisistema y los partidos internacionalistas. La unión será circunstancial e interesada hasta lograr el objetivo pretendido. En esta explosiva combinación, inevitablemente se recurrirá a la violencia, soterrada o visible, psicológica o física, institucional o social, contra quienes se oponen a sus pretensiones, estando preparados para recurrir en caso necesario a la fuerza extrema. Una vez consigan el poder y lo ejerzan, previsiblemente pasarán de ser falsas víctimas a verdugos que ejecutarán o violentarán a quienes no se sometan a su voluntad.

Formará parte de la estrategia del victimismo además de crear inestabilidad y desorden, presionar psicológicamente a las gentes para que se sientan a disgusto con la situación e intenten escapar de ella, por lo que querrán deshacerse de un problema que atribuirán a la explotación territorial de las nobles gentes del $\operatorname{lugar}^{20}$. En este caso poco tendría que ver con el exceso de racionalidad y de jurisdicción.

Los victimistas nacionalistas son conscientes de que una buena parte de la sociedad, sobre todo los que sufren de oikophobia, llevará al poder a quien no desea defender a la nación $\mathrm{y}$ prefiere entregarse sin condiciones a la presión lacrimógena de los victimistas. Salvo excepciones, el movimiento nacionalvictimista se llevará a cabo por una parte de la población contra un alto número de ciudadanos, con el resultado que adquirirá más fuerza si el movimiento tuviera lugar en una sociedad poco dispuesta a afrontar este tipo de situaciones. Confiarán vanamente en que el problema podría arreglarse con el transcurso del tiempo.

Al ser tan radical en su apariencia pacifista, es previsible que la estrategia de contención del victimismo nacionalista tenga límites y esté a la espera de debilitar al enemigo para pasar a una situación de conflicto armado. Es este un recurso cívico - la galería monstruosa de lo aparente- que empleará al objeto de situar al "represor" dentro de la enemistad diabólica. Siempre el victimista se creerá exculpado de sus acciones y denunciará al "opresor" como el origen de todos sus males, pasados, presentes y futuros. Por eso cabe esperar que en situaciones que estimara favorables utilice la violencia extrema.

Cualquiera que sea la respuesta del "represor", el victimista tendrá la propensión a radicalizar las acciones mediante una táctica que obligue al Estado, "violador de los derechos", a emplear la violencia, esperando que cause muchas víctimas. El motivo es que en un Estado de Derecho el nacionalvictimismo no podrá presentar víctimas auténticas, de modo que intentará que surjan de todas las maneras posibles.

Salvo los crédulos extremos, los ignorantes, y los ideológicamente interesados, se sabe que en un régimen constitucional-pluralista serán respetados los derechos de los ciudadanos. De ahí que se tenga que deformar la realidad extremadamente. Siendo previsible que sus oligarquías carezcan de sensibilidad, emplearán una estrategia martirológica que provoque el derramamiento de mucha sangre. Contarán con que siempre habrá unos cuantos lerdos

20 Porque actualmente el territorio para los defensores del universalismo, especialmente en Europa, no tiene mucha importancia. Lo reducen a su propio ámbito de posesión. 
que voluntariamente se encargarán de donar o suministrar sangre a la causa. Es decir, que los dirigentes victimistas harán todo lo posible para que surjan víctimas, tanto entre los suyos, poniendo en vanguardia a los voluntarios más estúpidos para ser sacrificados, como entre los que considera enemigos, dando curso al despliegue de la crueldad motivada por su ética falsaria.

De modo que la maquinaria victimista compondrá unos contenidos de moralina política cuyo eje central será la mentira socializada e institucionalizada. Debido a la falta de legitimidad de la corriente, tendrá que producir engaños permanentes destinados a crear falsas creencias y reproducirlas ilimitadamente. Por ello manipulará a la opinión pública, tanto dentro como fuera del territorio del que quieren apropiarse, para conseguir cada vez más adhesiones y aumentar la fuerza del movimiento. No obstante, lo más importante será concebir una estrategia preparatoria en diferentes áreas y niveles, al objeto de que se produzca una alienación colectiva. Teniendo presente este supuesto, las oligarquías suelen confiar en que siempre habrá mucha gente dispuesta a aceptar la sucesión ilimitada y sistemática de lo absurdo, y que nunca admitirán la sinceridad de su proyecto ya que se desmoronaría todo el engranaje sentimental lacrimoso. Causa por la cual, según explica Rene Girard (2006) el mayor esfuerzo lo destinará sobre todo a eliminar la realidad y como bien señala Nelson Espinal (2017) extender el malestar.

Como paso previo a la destrucción de todas las instituciones que no lograron controlar, la estrategia del nacional-victimismo será pacifista y revolucionaria. El victimismo nacionalista no lo compondrá un grupo homogéneo, ya que habrá diferencias ideológicas y personales del que formarán parte desde los aprovechados que buscan el poder y las rentas monetarias, hasta los grupos antisistema que intentarán provocar el desorden para destruir la civilización. La negatividad destructiva del movimiento se proyectará con la intención de hacer el mayor daño posible, aunque casi todos ocultarán sus verdaderas aspiraciones a fin de constituir una sociedad nacional-colectivista, aprovechando, en sentido faústico, el desarrollo tecnológico que permitirá controlar mejor a la ciudadanía.
Una vez el victimismo nacionalista tenga un numeroso apoyo, mediante una aptitud aparentemente pacífica y defensiva, intentará desmarcarse del poder político del Estado al objeto de componer sus propias estructuras oligárquicas. Motivo por el que confeccionará una estrategia de enfrentamiento utilizando los recursos más efectivos, desde los medios verbales, hasta la presión social en los diferentes ambientes sociales, incluidos los familiares. Elegirá el momento para mantener o elevar la tensión, utilizando cualquier medio que les acerque a sus pretensiones. Así, ante un gobierno débil conseguirá ir avanzando mediante el enfrentamiento, con algún pequeño retroceso - un paso atrás, dos pasos adelante (Lenin 1993)-, aproximándose cada vez más a sus fines.

Hay que recalcar que el victimismo independentista fundamenta el objetivo y la estrategia en la mentira consciente, a partir de la cual se iniciará todo tipo de procedimientos para conformar a las circunstancias. Entre más falsos y artificiosos sean los objetivos del victimismo, más necesidad tendrá de extender la mentira para persuadir a los individuos de querer llegar a conseguir el bien y la paz. Considerará prioritario contar con el número suficiente de sujetos para suministrarla a través de la educación y la propaganda. Con este medio-fin parcial monopolizará la educación para que los educandos se adhieran al movimiento de las falsas realidades. Esta es la causa de que reclamarán el derecho a engañar a la infancia, con el propósito de formar individuos desvirtuados, desprovistos de sentido común. Saben que para llegar a formar una personalidad basada en una creencia distorsionada sobre lo que es el bien y el mal es imprescindible penetrar y dominar cada conciencia individual. De modo que la propaganda victimista siempre tendrá la intención más retorcida: que las almas se corrompan y se entreguen a la causa falaz.

$\mathrm{Si}$ los dirigentes del proceso victimista carecen de honradez política, los enseñantes nacional racistas, les superan en indignidad por su falta de honestidad intelectual. Esta clase de docentes -educadores propagandistas destinados a ideologizar a los que determinan como poseedores de un intelecto colectivo superior, esto es, un sistema neuronal mucho más desarrollado-, en sus diferentes niveles, son vulgares transmisores de la mentira 
¿Un nuevo tipo de racismo?

The national-victimism: between the right of resistance and the right of self-determination.

A new type of racism?

extraídos de la basura intelectual y de la abyecta ignorancia voluntaria. Con estas artimañas vulgares, pero previsiblemente efectivas, el victimismo nacionalista no pasará de ser un pensamiento mediocre y banal, que solamente funcionará con la mentira sistemática y en los frontispicios en que se colocan los ingenuos para alcanzar el grado de tontos falsos.

$\mathrm{Su}$ estrategia será un éxito en cuanto la oligarquía ${ }^{21}$ de la corriente nacional-victimista haya adquirido la capacidad suficiente para engañar a los incautos y a los predispuestos a aceptar sus caprichos. Por lo cual nunca querrá hacer el bien ni siquiera a sus simpatizantes. Tampoco detendrá o limitará sus acciones, aunque perjudique a las personas inocentes - no hay inocentes si no se suman al movimiento-. Entre otras razones porque para el moralista los que no compartan el objetivo o la estrategia les declarará culpables y no merecerán ser respetados. Peor aún. Según la nueva moral de combate que habrá de regir, se les deberá aplicar cualquier clase de tratamiento cuyo buen resultado pueda eliminar su peligrosidad. Por eso sus activistas habrán de ser considerados verdugos para quienes no acepten sus premisas, teniendo que sufrir la violencia psíquica o física de los "oprimidos". De modo que las verdaderas víctimas serán los que padecerán la presión y persecución de los verdaderos represores: los victimistas.

El nacional-victimista, transformista diabólico, tendrá que aparentar ser un inocente pacifista, con el inconveniente de que no podrá usar la violencia masiva, ya que se esfumaría su posición tragicómica y podría tener la respuesta más temida. Claro que, en potencia, una vez haya sembrado y extendido el odio y la sospecha en las relaciones sociales ${ }^{22}$, cuando las circunstancias lo permitan, probablemente propagará el terror sobre quienes no están de acuerdo con sus planes u objetivos.

Forma parte de la estrategia la posibilidad de que la benevolencia del Estado o del gobernante con las falsas victimas y el trato injusto a los verdaderos reprimidos, será uno de los motivos principales por lo que

21 La oligarquía buscará siempre el negocio y el poder. Ella será la que cree la estrategia victimista. Herbert Spencer (2012) comentaba hace muchos años que "la estrategia del victimismo, de la falsa solidaridad, de la culpa social y del colectivismo es el rentable negocio de la minoria" (Página 29) que dejará en la miseria a cualquier próspera unión. 22 También entre los propios simpatizantes. el movimiento conseguirá sus propósitos. La oligarquía victimista presupone que el gobernante del "Estado opresor" optará por debilitarse voluntariamente, $\mathrm{y}$, además, su triunfo lo alcanzará si en vez de apoyar a los que rechazan la discriminación y quieran seguir dependiendo del Estado, les negase su apoyo. En el manual nacional-victimista figura que los gobernantes estarán obligados a proteger sus derechos, incluidos los políticos. $\mathrm{Y}$ que, si gobiernan melifluos personajillos en el Estado, dejará desamparados a los que sufran el hostigamiento o persecución del nacionalismo.

Al presentarse como falsas víctimas de una “opresión" inexistente ${ }^{23}$, el nacional-victimista es consciente de que tendrá muchos apoyos, ya que siempre hallará individuos dispuestos a aceptar acríticamente su discurso. Igualmente serán conscientes de que dependerá de su capacidad operativa para que sus proyectos lleguen a ser apoyados por otros Estados y por los individuos "sensibles" ante la injusticia. De ahí que la estrategia consistirá en dedicarse a hacer un ejercicio político que requerirá una constancia ininterrumpida, construyendo una maquinaria que funcione como productora permanente de la adaptación de la mentira a la táctica del presente. Por ello, en la práctica, será menos importante el objetivo que la estrategia, porque de ella saldrá lo más conveniente para lograr el fin perseguido: la utilización espuria de los medios, la forma en que las acciones son llevadas a cabo, los procedimientos, etc.

Si este movimiento político-social persevera, progresivamente arrastrará hacia él a buena parte de la sociedad civil. Con una estrategia eficaz sabrá aprovecharse de la benevolencia de los buenistas con los delincuentes y demás elementos antisociales, teniendo la seguridad de que sus dirigentes serán tratados con respeto, aunque estén corrompidos. Con esta lógica se supondrá que entre peores sean los dirigentes, más posibilidades tendrán de elevarse al liderazgo para dirigir a las turbas enajenadas que serán convenientemente utilizadas como mercancía humana de escaso valor, potencialmente dispuestos a sacrificarlos si la situación lo requiriera.

A diferencia de las corrientes que luchan por la libertad y la justicia, la nacional-victimista

23 Vid. Rafael Núñez Florencio, La actual superioridad moral del victimismo. Disidentia. 13 de julio de 2018, página 3 
cuenta con que podrá actuar impunemente sin limitaciones, al saber que estarán apoyados por las instituciones del Estado del que forman parte, motivo por el que sus acciones no tendrán consecuencias políticas negativas. En el mismo sentido forma parte de su estrategia utilizar el Estado de Derecho, ya que están seguros de que no transgredirá sus propios fundamentos. Las garantías jurídicas que ofrece este tipo de Estado serán utilizadas mudándose en garantismo discrecional. Por ello reclamarán la protección de sus derechos, aunque nunca respetarán los derechos de quienes se oponen al movimiento. De modo que los derechos subjetivos se convertirán en instrumentos de fuerza de la estrategia para debilitar al "opresor". De modo que obligará a que los nacional-victimistas estén atentos para provocar las contradicciones del Estado y aprovecharse de los miedos y complacencias de la sociedad. Por ejemplo, utilizarán una vieja treta política: la de intentar dividir al “opresor". Lo conseguirán cuando, en contra de su nación y del resto del cuerpo político, una parte de la población se ponga de su lado. Lo que explica que siempre interesará que haya muchos traidores a la nación. En cambio, para atraerles a su causa, perseguirá a los que rechazan el único patriotismo posible: el que habrán de tener todos los ciudadanos que creen pertenecer a una aparente nación que busca formar un nuevo Estado.

Corrientemente casi todas las actividades de los victimistas se harán con el apoyo económico de los que juzgan como instituciones opresoras, con el desinteresado propósito de no sufrir ningún desgaste patrimonial individual. Cabría incluso que el gobernante opresor secundará los latrocinios de la oligarquía victimista. De modo que el dinero de los ciudadanos opresores será utilizado, entre otras actividades, para subvencionar al nacional-victimismo y pagar a los intelectuales y periodistas que se encargarán de justificar los objetivos, inventarse hechos, dándoles el cariz favorable que requiere el movimiento y cambiando a su conveniencia el sentido verdadero de los sucesos. Posiblemente destacará la labor del periodismo victimista -en realidad creadores de la ideología informativa-, y el intelectualismo mercenario - profesionales contratados para acabar con la verdad- al constituir la vanguardia de los que carecen por completo de ética.
Los nacional-victimistas no sólo manipulará la información para que no se descubran sus falsedades, sino que la utilizarán como una fuerza distorsionadora de la realidad. Igualmente esperarán que los gobernantes propongan el diálogo, esto es, la cesión sin contrapartidas. Previsiblemente tras una petición concedida ${ }^{24}$ surgirán otras muchas, porque la maquinaria victimista no podrá detenerse, ni aun después de alcanzar el objetivo.

Esta estrategia nacionalista contará con que el aparente opresor no podrá responder de parecida manera, por lo que se enfrentará al movimiento utilizando medios represivos o retrocederá sin ofrecer resistencia. Si no toma decisiones de defensa de la unidad política, se deberá a que por cobardía o desidia no querrá actuar contra el victimismo. Este contará con que el opresor se reprima a sí mismo y no tome ninguna medida de fuerza efectiva, perdiendo la batalla política. Es decir, esperará que no emplee la fuerza ni que actúe inteligentemente debilitando la posición del victimista.

En cuanto la sociedad entre en una especie de acomodamiento a la situación y no quiera abordar los problemas que le afectan, o haya perdido el sentido patriótico de pertenencia a una comunidad política, significa que dejará de tener una perspectiva de futuro, y un sentido de responsabilidad para con su nación. La primera de las consecuencias será el abandono vil de los que se encuentran indefensos ante quienes les ha declarado la enemistad.

\section{EL GOBERNANTE COMO DOBLE AGENTE DEL NACIONAL-VICTIMISMO}

Si la sociedad política es débil o acomodaticia, no será difícil que llegue a coincidir el interés personal del gobernante del Estado con los intereses de las oligarquías victimistas. Entonces se podrán repartir los frutos que produce la "amistad" entre los que quieren mantenerse en el poder y los que buscan conquistarlo. Será un ejercicio político que expresará la hez humana con toda su miseria. En una situación tan deleznable, no habrá héroes entre los nacionalistas, ni en la sociedad indiferente, sino villanos y traidores.

24 Incluso el político menos capacitado para ejercer sus funciones sabe que podrá ocurrir 
¿Un nuevo tipo de racismo?

The national-victimism: between the right of resistance and the right of self-determination.

A new type of racism?

Aunque el gobernante sea consciente de que perderá fuerza una vez que se reduzca el territorio y la población del Estado, preferirá mantenerse en el poder y eliminar un grave problema. Entonces se abrirá otra posibilidad: un alto número de ciudadanos podrían convertirse voluntariamente en siervos de quienes en verdad los explotan. Por tanto, el nacional-victimismo habrá conseguido lo que en muchos países sería imposible: la colaboración entre el sentimentalismo racista y el gobierno traidor a su país.

La actuación de gobierno frente al nacionalvictimismo dependerá de la fuerza del Estado, de la voluntad e inteligencia de las oligarquías, de las diferentes personalidades políticas y de la capacidad de la sociedad para influir, acertadamente o no, en todos ellos. De forma sintética se podrían reducir a dos tipos: $1^{\circ}$. Quienes no están dispuestos a desprenderse de un territorio, y $2^{\circ}$ los que se plieguen a las exigencias de la corriente nihilista. Esta simplificación está justificada porque el problema se podría afrontar con diferentes estrategias. Nos centraremos más en el papel del gobernante que querrá resolver el problema mediante concesiones continuas al movimiento, apoyándole, pues, cuando menos de manera indirecta. Si bien el gobierno es un poder determinado por la Constitución, políticamente podría desvincularse de su máxima obligación: defender la unidad de la nación y asumir la estrategia del nacionalvictimismo. En este sentido, al aceptar las exigencias de sus componentes, se convertirán para él en adversarios o compañeros, mientras que a los ciudadanos contrarios a la independencia les encuadrará en la categoría de enemigos.

No obstante, al ser el nacional-victimismo un movimiento moralista, convierte a su contrario en enemigo y además culpable. Previsiblemente intentará no sólo vencer su resistencia, sino eliminarlo, como un derecho moral universal, con el fin de purificar la vida humana desde una perspectiva nacional-internacionalista. Este derecho moral implica a su vez el derecho a eliminar al culpable.

Por este motivo, si el gobernante quiere evitar cualquier oposición, intentará reducir las libertades de los integrantes del cuerpo social e imponer otra clase de ley: la del miedo. Dicho de otra manera. En vez de acudir a la defensa del Estado aplicando la normativa constitucional al caso, el estado de excepción, dará el paso revolucionario de apoyar a unas pretendidas colectividades históricas. Naturalmente después de un fructífero diálogo -en realidad un soliloquio en el que mandan los representantes del nacional-victimismo sobre el entreguista-, aceptará sus fundadas razones. Para entonces, el gobernante ya habrá cometido otro atropello aún peor: ejercer la potestas arbitrariamente sobre la parte mayor $o$ menor de la sociedad que no acepta la ruptura.

La estrategia de un gobernante dispuesto a conceder las peticiones delnacional-victimismo independentista será ralentizar sus objetivos engañando a la sociedad y manteniendo una actitud pasiva y condescendiente con el rebelde. Asimismo, tendrá que negarse a aplicar las leyes de defensa de la nación, e incluso les dará el apoyo financiero suficiente para que, con el ánimo de ralentizar el movimiento con concesiones, puedan continuar con sus actos de rebeldía. Este tipo de gobernante, aparte de tener como principal objetivo mantenerse en el poder, tratará de impedir que, si asciende al gobierno un persona responsable y dispuesta a afrontar el grave problema, le sea imposible restituir la fuerza y detener el traspaso de fondos monetarios de la nación al territorio secesionista.

Lo cierto es que un gobernante que únicamente quiera seguir en el poder no se comprometerá con su colectividad, sino consigo mismo y con sus acólitos. Por conveniencia será un aliado del nacional-victimismo, aunque con esta casuística moral tampoco estaría capacitado para concebir una estrategia de respuesta a la acción victimista. De este modo no tendrá que valorar los riesgos, dado que su intención es hacer concesiones a tenor de las peticiones. Tampoco tendrá un plan de anticipación para reducir en lo posible lo imprevisto, confiando en que no habrá ningún enfrentamiento serio con los victimistas.

Un gobernante entreguista se caracterizará por su falta absoluta de sentido patriótico, aunque aparentará tener ideales elevados. Lo más llamativo es que participará del aparente patriotismo de los independentistas. En la práctica, el gobernante pasará a ser una especie de poder constituyente desde el propio Estado por su apoyo a formar otra unidad política. De modo que se convertirá en socio del victimismo, 
al convertirse en un gestor y dador universal para favorecer a los rebeldes. Es decir, que será un interesado patriota de la parte del territorio que quiere independizarse, al rendir un servicio fundamental para la aparición de una nueva unidad política asumiendo el papel de agente o gobernante doble. Motivo por el que siempre estará dispuesto a entregar el territorio que exigen los victimistas, si bien de cara a la opinión pública, apelará a la táctica del diálogo y la posibilidad del acuerdo, ocultando a la sociedad que representa un ejercicio de un poder rendido, de un vencido sin lucha o un cooperador necesario.

Puesto que las libertades que reclaman ya las poseen, con el fin de atemperar su activismo radical, el gobernante entreguista otorgará privilegios respecto al resto de la población, aumentando así la desigualdad y la injusticia, haciendo inefectivo un principio fundamental del Estado de Derecho: la igualdad jurídica, siendo el propio gobernante el que anulará el principal fin de la política y el mayor responsable de la violación de un principio fundamental del ordenamiento jurídico.

Aunque no sea una novedad en la historia política, se infiere que lo que causa mayor estupor será encontrarse ante un modo de ejercer la política desde el gobierno contra la nación, ya que actuará como si fuera uno de sus enemigos. Siendo un explotador deleznable y traidor a su propio pueblo, contribuirá a formar un nuevo estado saqueando a sus conciudadanos y entregando el producto de su botín a los victimistas.

Esta atención del gobernante no significa que haya perdido el interés por el dominio. Como es lógico nunca estará dirigido a los nacionalvictimistas, sino que lo impondrá despóticamente contra los que respetan el orden constituido, poniendo el máximo celo en reprimir a los ciudadanos que se opongan a la cesión de su territorio. Por eso todo el ejercicio de servilismo político del gobernante con los victimistas, lo transformará en despotismo y arbitrariedad contra sus ciudadanos, incluidos los que compartan su moralina.

Por consiguiente, la política del gobernante consistirá en una especial mezcla, consistente en ser un abogado defensor de la rebelión victimista a fin de sostener las aspiraciones colectivas, y un combatiente ideológico contra quienes se opongan a sus decisiones. Al apoyar la corriente separatista le servirá también para desnacionalizar el Estado. Actividad que supondría dejar de representar a la mayor parte de la sociedad política incumpliendo la obligación de mantener el orden público, sustituto de la superada Razón de Estado. La tarea desnacionalizadora del gobernante implicará hacer un cambio radical si elimina de raíz buena parte de la política que defiende el Estado y su historia.

Por su parte, al objeto de crear un componente patriótico sensiblero, los nacional-victimistas se inventarán un pretérito que justifique el rechazo al que califican como Estado tiránico, que el gobernante se encargará de ayudar con sus legiones de pedagogos y pseudohistoriadores mediante la invención de una historia, al mismo tiempo que deleznando el pasado de su Nación.

Suele suceder que el gobernante al manifestar una debilidad acomplejada, provocará el desprecio del nacionalvíctimista. Si además el gobernante es irresoluto irritará también a las verdaderas víctimas. Y como explica Julien Freund (1981) siendo probablemente melifluo, incapaz de entender las consecuencias de un ejercicio político entreguista, previsiblemente no acudirá a la experiencia del pasado, en donde quedará probado que la debilidad voluntaria provocará más violencia, y que la postración en el futuro podría generar tragedias que podrían evitarse. Así como señala Julien Freund (1968), un gobernante que no emplee la fuerza legítima ante situaciones de ruptura con el orden constitucional, y más gravemente frente a un movimiento secesionista no le quedará más remedio que rendirse cobardemente ante él.

$\mathrm{Si}$ un gobernante entreguista actúa sin importarles las graves consecuencias de que un territorio se independice, se deberá a que estará apoyado por una parte destacable de la población, sea por pasividad de los individuos acomodaticios despreocupados de la sociedad política y que prefieren estar ligados consigo mismos, o por simple traición, algo corriente en no pocos individuos que se realizan como humanos apoyando al enemigo. Se iniciará entonces el desmembramiento del cuerpo social que terminará con la destrucción del cuerpo político. Y si las fuerzas armadas, que tienen como misión mantener la unidad política y defender el territorio de los enemigos externos adoptan la misma actitud, permitiendo que el 
¿Un nuevo tipo de racismo?

The national-victimism: between the right of resistance and the right of self-determination.

A new type of racism?

gobernante entregue un territorio al victimista, la consumación de la destrucción será un hecho.

En resumen, que no habrá ningún choque dialéctico al pasarse de la tesis expresada por el nacional-victimismo al comportarse como un poder en acción desmembrador, con tendencia a crecer, que irá acompañado del poder entreguista del gobernante que retrocede a fin de transfigurarse y autolimitarse a una tesis con la celebración del éxito de ambos, sin la fuerza opositora de la antítesis. De modo que se puede considerar al gobernante $\mathrm{y}$ sus huestes los padres fundacionales y los principales impulsores del poder constituyente del nuevo estado.

\section{LA UTILIZACIÓN DEL DERECHO DE AUTODETERMINACIÓN ${ }^{25}$ POR EL NACIONAL-VICTIMISMO}

El nacionalvictimismo que sólo es una novedad en la manera de enfrentarse al Estado del que forma parte, nunca podrá ser un ideal de emancipación para los pueblos sometidos, de modo que no podrá acogerse al derecho de autodeterminación. Si, además, busca un objetivo espurio, todo el movimiento carecerá de una relación con una causa justa ${ }^{26}$.

Por lo demás, el nacional-victimismo pretende adaptar la situación actual la idea roussoniana que una nación está compuesta por un conjunto de territorios sometidos a la convención y a la ley, cuyo cuerpo político se halla en un contexto histórico que necesita renovarse. A partir de esta idea se podrá justificar que los ciudadanos puedan tener la voluntad de mantenerse en la unidad política o salirse de ella ${ }^{27}$. En realidad,

$25 \mathrm{El}$ derecho de autodeterminación está recogido en el primer precepto del Pacto Internacional de Derechos Civiles y Políticos, asi como en diversas resoluciones de la Asamblea General de la Organización de Naciones Unidas (la 1514 (XV) y 1541 (XV) sobre la descolonización y la 2625 (XXV) extendida a otros ámbitos; 1803 (XVII) relativa a la soberania de los recursos naturales).

La libre determinación implica la plena capacidad para decidir la formación de un Estado independiente y también la integración de un Estado ya existente. Este "pueblo" que se refiere el derecho Internacional será el que esté sometido al colonialismo. "En el estado actual del Derecho internacional no hay un auténtico derecho de autodeterminación fuera de las situaciones de dominio cultural o por la fuerza" (López y Perea 2018, página 41)

$26 \mathrm{La}$ autodeterminación que posee unas connotaciones políticas y jurídicas, procede de la combinación del derecho de resistencia de Martin Lutero, John Knox y de la obediencia politica de Jean Calvin.

27 Aqui de nuevo hay que remitirse a la idea leninista de emancipación de los pueblos. Motivo por el cual el colectivismo apoyará el movimiento nacional-victimista. la autodeterminación no es un derecho ni una teoría política. Por eso considerar la autodeterminación como un derecho "pese a lo difuso de sus contornos", se estará otorgando "el rango de derecho", a una idea "que carece de categoría y nobleza” (Martínez 2007, Página 357). Porque, dice el profesor Juan Antonio Martínez Muñoz (2007), la autodeterminación no es otra cosa que "auto-indeterminación de cuándo es políticamente reclamable" (Página 356).

Tampoco el derecho de resistencia es un derecho incuestionable. Más bien ha de ser tenido por una forma de actualización política que defiende intereses de diversa clase, apelando a una supuesta opresión. En realidad, lo que se querrá justificar es el derecho a la insurrección. Ahora bien, la negación del derecho de resistencia no implica que en los sistemas políticos en que se desprecia a la vida humana, deba imperar un conformismo servil de la sociedad. En estos casos cabrá admitir el derecho de resistencia, sin incluir la separación de la nación. Al utilizar el nacionalvictimismo este derecho se percibe sus verdaderos propósitos, especialmente cuando califica al régimen constitucional-pluralista. Algo lógico ya que forma parte de la variada gama de potenciales despotismos, manifestándose en el deseo de imponer su voluntad a los ciudadanos que no admitan la separación política. Esta es la mejor prueba de que no respeta la libertad de los demás conciudadanos.

Si el nacional-victimismo apela al derecho a autodeterminarse, en cambio, nunca admitirá el derecho de los ciudadanos a respetar la legalidad y a seguir perteneciendo a la Nación. Quiere decirse que violar los derechos fundamentales de los ciudadanos contrarios al movimiento supondrá que el victimismo pacifista ejercerá una presión soterrada inaceptable en un Estado de Derecho, que sólo es compatible con la normalidad y el orden. Por ello la insurgencia del nacionalvictimismo estará fuera de la ley, y en el caso de conseguir sus fines, actuaría inevitablemente de forma despótica o tiránica. Por tanto, el derecho de resistencia o rebelión invocado por el nacionalvictimismo no es sino una voluntad política que se aparta de la ley, que nunca permitiría una insurrección pacífica

Porque, en palabras de Lenin (1973), lo que quiere el colectivismo es la "completa igualdad de derechos de las naciones; derecho de autodeterminación de las naciones; fusión de los obreros de todas las naciones..." (Página 71). 
si estuviera en el poder y reprimiría cualquier tipo de acciones contrarias a su voluntad.

En cualquier caso, el nacional-victimismo demostraría no solo contradicciones, sino que la fuerza del nacionalismo es muy superior a cualquier idea de solidaridad internacional. Si lograra sus objetivos sería una vez más una prueba del fracaso del internacionalismo a la hora de construir una auténtica sociedad internacional.

El objetivo del nacional-victimismo deberá ser juzgado a partir de una figura jurídica nueva: secesión por robo territorial, es decir, expropiación ilegal por un movimiento de ciudadanos de un área terrestre y marítima de su Nación propiedades públicas y privadas. Dicho de otra forma, que el nuevo estado devendrá una propiedad pública que quedará en manos de unos ladrones. A lo que se sumarían las propiedades privadas que forman parte del orden jurídico legítimo. Con ello, desde la perspectiva constitucional, se producirá un cambio trascendental, puesto que el rapto de un territorio nacional quedará elevado a principio divino constitucional del que derivarán los valores que serán la base de la nueva institución. La relativa novedad histórica no será la ocupación, sino la incorporación de una propiedad territorial por la voluntad basada en la fuerza.

El éxito del nacionalvictimismo quebraría la tendencia a la cooperación universal, y aumentarían las probabilidades de conflicto en el sistema internacional ${ }^{28}$. Además, se convertiría en modelo de lo que podrán hacer las oligarquías deseosas de poder en otros Estados. Es decir, que igualmente sería un ejemplo para quienes juzguen que las leyes de los Estados de Derecho son producto de una voluntad discrecional despótica, creyéndose legitimado a desobedecer la normativa opresora. Se abre así un modo de justificar cualquier desvinculación secesionista, que pretenderá ser calificada como un acto de libertad cuando se estime que un Estado se está imponiendo sobre la parte más

28 Un independentista siempre podrá justificarlo apelando a una presumible colonialidad, o cualquiera de las jerigonzas habituales; incluso justificándolo con una resistencia progresista de adaptación moderna. Así, dice Pablo Font Oporto (2018), que "en el ámbito del derecho positivo, más allá de la desobediencia civil y la resistencia como mera oposición, es fundamental una resistencia propositiva que, en el ejercicio de la autonomía y la autodeterminación, devengue en una alter-organización" (Páginas 207 y 208). El derecho de resistencia civil en Francisco Suárez. Virtualidades actuales. Granada. Comares. 2018, páginas. 207 y 208 selecta de sus componentes -la superioridad racial de los que viven en un territorio-. En el fondo, el nacionalvictimismo siempre operará con la indeterminación política y jurídica, y, al falsear el significado de la verdadera liberación, convertirá todo deseo propio en derecho colectivo.

En el momento actual el derecho de resistencia y rebelión contra la opresión, el victimista sólo admitirá concesiones temporales. Lo que implicaría trasladar momentáneamente funciones vitales del Estado, hasta que llegue la definitiva soberanía al nuevo estado, al territorio que quiere independizarse. Ahora bien, el nacional-victimismo nunca se contentará con estas concesiones, sino que exigirá la cesión completa de la soberanía que tiene sobre el territorio. En el espacio que transcurra hasta la independencia, salvo que ocurra de forma rápida, probablemente las transferencias consistirían en ir cediendo cotas de poder.

Una vez que se alcanza el objetivo de formar un estado, el nacional-victimismo justificará el paso del derecho de autodeterminación, al derecho de defensa y preservación de lo conseguido. Dicho de otro modo, los victimistas, ya voluntariamente desprovistos de su primitiva autocalificación, cambiarán la estrategia: superado el derecho de autodeterminación, impondrán el derecho de defensa y protección únicamente para los habitantes que acepten el nuevo estado.

A la par que defensor de la autodeterminación, el nacionalvictimismo defenderá el derecho a la expansión territorial. De lo que se deduce que en un tiempo más o menos próximo, el nacional-victimismo inevitablemente justificará la iniciación de acciones expansivas para "defenderse" contra lo que antes fue su Nación. La intención será legitimar el derecho de defensa mediante un juicio moral previo, iniciando una estrategia de lucha armada preventiva contra los opresores.

En realidad, hay que imputar a la veleidad imperialista el paso siguiente a la formación del estado, ya que, por lo general, el racismo se manifiesta y se justifica en un dominio de los inferiores, así como una revancha por su antigua opresión. Al creerse superiores a aquellos que les oprimen, los nacionalistas están obligados a incorporar el territorio de los antiguos represores. Si no hay una fuerza que le contrarreste se pasará de sufrir "represión" 
The national-victimism: between the right of resistance and the right of self-determination.

A new type of racism?

a invadir los territorios en que haya una similitud de cultura, lengua o raza. El nacionalvictimismo haría una nueva adaptación de la teoría del espacio vital (Lebensraum), a partir de una cosmovisión depredadora. Lo que significa que estará contagiado de un especial veneno a partir del cual formarán una sociedad asentada sobre bases revanchistas y que querrá devolver al "opresor" los presuntos daños producidos. El odio continuará, aunque se consiguiera el objetivo y la mentira tendrá que seguir nutriéndose de los sentimientos más negativos aun desapareciendo las circunstancias anteriores.

\section{CUANDO EL SISTEMA POLÍTICO ES INCAPAZ DE CONTROLAR AL NACIONAL-VICTIMISMO}

Cualquier Estado fuerte y bien gobernado tendrá muchas posibilidades de derrotar al nacional-victimismo. La relación de fuerzas es simple: Por un lado, el Estado y, por otro, el nacional-victimismo, que oculta su agresiva fuerza con una moralina-juridicidad $y$ su pretensión de constituirse como potencia.

Cuando el nacionalismo independentista adquiere una fuerza como para crear al Estado un problema de extrema gravedad, demostrará la mala composición y debilidad del sistema político. Según Maquiavelo (1999), la responsabilidad de que en su seno se hayan formado unas facciones e impere el desorden en una parte del territorio, hasta el punto de ocasionar su pérdida y una posible tragedia colectiva, se debe al gobernante, a las instituciones y a las fuerzas políticas. Esta coincidencia institucional significaría que el régimen estaría mal constituido o carecería de eficacia para mantener la unidad política. Pero cuando el sistema político demostraría su mayor ineficacia y degradación sería si desde las propias instituciones del Estado se apoyara o provocara la ruptura.

El nacionalismo victimista solo temerá a un Estado bien conducido por un gobernante que utilice su fuerza sin falsos imperativos éticos, endurecido las leyes contra la insurrección y la violencia política. En un caso extremo el gobernante podría defenderse lícitamente con todas las fuerzas contra el nacionalvictimismo $^{29}$.

$29 \mathrm{Si}$, además, lleva a cabo un inteligente ejercicio político, podria desbaratar su estrategia.
Por el contrario, todo aumento de poder del nacional-victimismo probará que no siempre el sistema representativo es el idóneo, sobre todo si se diera cabida institucional a quienes apoyen el independentismo racista. Porque la Nación deberá estar por encima de cualquier régimen político, incluyendo el democrático, que sólo es un medio de la sociedad para controlar el poder, y del Estado, que estará obligado a utilizar los instrumentos de que disponga para defenderla, incluso cuando la mayoría, en un momento dado, sea pasiva o rupturista. Al fin y al cabo, nunca podría estar al mismo nivel la voluntad presentista, generalmente muy cambiante, con la solidificación histórica de tantas centurias de formación identitaria. Si la mayoría de los ciudadanos son débiles y pasivos, será la parte de la sociedad responsable de su nación, la que deberá tomar medidas para defenderla.

Una de las consecuencias más negativas del posible éxito del nacional-victimismo es que llevaría a la colectividad al declive y a la desprotección ante los posibles enemigos exteriores. En el interior del Estado se habría conseguido que el gobierno oligárquico y su caterva de seguidores aumentasen la sujeción del ciudadano mediante la represión y la arbitrariedad, pasando del pactum societatis al pactum subjectionis, acrecentando, por tanto, la servidumbre. Asimismo, se destruiría la igualdad, porque si bien se reconoce al movimiento nacional-victimista el derecho de resistencia, en cambio, no se admitirá a los demás ciudadanos a ampararse en este derecho, quedando desautorizados a actuar de la misma manera.

\section{CONCLUSIONES}

Lógicamente en esta exposición no se han agotado los rasgos del victimismo, pudiendo aparecer, según el contexto, características propias según sea el Estado en que aparezca el movimiento. En cambio, no renunciarán a los postulados generales y a los rasgos principales de la estrategia. Aunque el nacionalvictimismo forma parte de una época en el que la mayoría de las sociedades occidentales desarrolladas son pacifistas, en él hay una ocultada violencia que en cualquier momento podría manifestarse. No en vano el nacionalvictimismo es una estrategia de poder racista basada en una mentira que fácilmente se podría descubrir: la inventada opresión al resistente. 
Si llegase a triunfar el nacional-victimismo se convertiría en un modelo de conquista del poder y un modo de provocar una disgregación social. La dialéctica del éxito sería: el triunfo de la voluntad contra la indiferencia; la presión constante sin violencia visible, contra el vacío sumiso. Y si consiguiera controlar a las instituciones, formaría un régimen autoritario o totalitario, ya que habrá de sustituir el orden por la organización despótica y el control burocrático. Se infiere que una vez constituyera un estado, empleará todos los viejos métodos del despotismo político contra quienes se opongan a la voluntad de sus oligarquías y al fanatismo de la plebe.

En el contexto internacional ciertas medidas que se tomen en la política interior podrían tener relevancia en la política internacional, en un grado que dependerá de la fuerza de cada Estado. Y en una confrontación de intereses, el Estado que se debilite tendrá más posibilidades de salir perjudicado. La desestructuración y la división de un país supondrá, por el sistema de fuerzas, que disminuirá su capacidad en la política internacional. Por eso los victimistas podrían ser utilizados por otras naciones para debilitar a un país adversario o enemigo. De manera que los Estados interesados lograrían un doble éxito: debilitar la fuerza del "Estado opresor", y tenerlos como subordinados, por lo que tanto a unos como a los otros serían mucho más fáciles de dominar en tiempos posteriores. Se ve claramente que "el derecho a tener derechos" en el sistema internacional podría conducir no solamente al conflicto, sino a eliminar los derechos de los que no comparten la misma posición ideológica.

$\mathrm{Si}$ el nacional-victimismo consiguiera los objetivos, habría triunfado un modo de hacer política ajena al derecho internacional y a los derechos humanos, al aparecer unas posibilidades para violar varios derechos que iría en detrimento de la reducción de las medidas de fuerza en el sistema internacional. Se pasaría de una situación de respeto a los derechos de los que serían ciudadanos como los demás, al sometimiento a un Estado y un régimen despótico que impediría el libre ejercicio de los derechos políticos y civiles. Este Estado jamás permitiría que los ciudadanos opuestos a la separación reclamasen el derecho de autodeterminación.
La causa es que el nacional-victimismo tendrá la pretensión de transformar los derechos subjetivos en política demonológica, ya que quien rechace la formación de una nueva unidad política se convertirá en enemigo (hostis) diabólico. Su estrategia basada en un aparente pacifismo, tendrá la pretensión de frenar una acción general violenta contra ellos. En cambio, no se apagará el deseo exterminador del nacionalvictimismo, quedando ocultos dos supuestos que probablemente determinen un conflicto futuro. El imperialismo de la unidad política a la que pertenecen, y el odio colectivo, e incluso personal, dentro del ámbito territorial que dominen, les llevará a negar incluso la existencia física de los componentes de la sociedad que rechacen la independencia.

Para alcanzar sus fines, el nacional-victimismo buscará la destrucción de la "potencia del Estado". Una vez conseguido, los oponentes al nacional-victimismo dejarán de ser ciudadanos, porque "cuando una ideología racista es la que domina, el enemigo se considera esclavo por naturaleza" (Freund 1968, Página 628). Quiere decirse que el nacionalismo no sólo querrá la independencia, porque al moralizar lo político con los máximos sentimientos negativos, nunca se conformará con el primitivo objetivo, al tener que dar curso a su extirpación y eliminar completamente al que consideran enemigo. Como señala Freund (1968), esta actitud procede del odio y el resentimiento por haber considerado que el enemigo es un culpable absoluto, causante de todos los dolores que cada individuo haya tenido en su vida y que sólo se podrá aliviar, en parte, con su desaparición como chivo expiatorio.

\section{FUENTES DE INFORMACIÓN}

\section{Fuentes bibliográficas}

$\mathrm{M}^{\mathrm{a}}$ José Falcón y Tella (2009). ¿Y si no castigásemos? en, Teorías y aplicaciones sobre la noción de responsabilidad jurídica. Ángel Sánchez de la Torre y Isabel Hoyo Sierra (editores), Madrid, España: Dykinson y Real Academia de Jurisprudencia y Legislación.

Campbell, Bradley y Manning, Jason (2018). The Rise of Victimhood Culture. Microagressions, Safe Spaces, and the New Culture Wars. London, Reino Unido: Palgrave Macmillan. 
El nacional-victimismo: entre el derecho de resistencia y el derecho de autodeterminación.

¿Un nuevo tipo de racismo?

The national-victimism: between the right of resistance and the right of self-determination.

A new type of racism?

Rene Girard (2006). Los orígenes de la cultura. Conversaciones con Pierpaolo Antonello y Joao Cesar de Castro Rocha. Madrid, España: Trotta.

Spencer, Herbert (2012). El hombre contra el Estado, Madrid, España: Unión Editorial.

Freund, Julien (1981). El fin del Renacimiento. Buenos Aires, Argentina: Editorial de Belgrano.

Freund, Julien (1968). La esencia de lo político. Madrid, España: Editora Nacional.

Font Oporto, Pablo (2018). El derecho de resistencia civil en Francisco Suárez. Virtualidades actuales. Granada, España: Comares.

Lipovetsky, Gilles (1986), La era del vacio. Ensayos sobre el individualismo contemporáneo. Barcelona, España: Anagrama.

Von List, Guido (2008), Die Religion der ArioGermanen in ihrer Esoterik und Exoterik, Graz, Austria: Geheimes Wissen.

\section{Fuentes electrónicas}

Maquiavelo (1999). El Príncipe. Recuperado del sitio de internet: https://ocw.uca.es/ pluginfile.php/1491/mod_resource/content/1/ El_principe_Maquiavelo.pdf

Martínez Muñoz, Juan Antonio (2007). La autodeterminación. En Anuario de Derechos Humanos. Nueva época. Vol. 8. Páginas 325264. Recuperado del sitio de internet: https:// eprints.ucm.es/11378/1/Autodeterminacion.pdf

López Martín, Ana Gemma y Perea Unceta, José Antoni (2018). El intento secesionista en Cataluña a la luz del Derecho internacional. En Agenda Internacional. Año XXV, $\mathrm{n}^{\circ}$ 36. Páginas 25-43. Recuperado del sitio de internet: http://revistas.pucp.edu.pe/index.php/ agendainternacional/article/view/20319/20269

Espinal Báez, Nelson (2017). El victimismo como categoría política. Recuperado del sitio de internet: https://www.diariolibre.com/ opinion/en-directo/el-victimismo-comocategoria-politica-CB8535589
Escohotado, Antonio (2003). La Remora Victimista. Recuperado del sitio de internet: http://www.escohotado.com/articulosdirectos/ laremoravictimista.htm

Núñez Florencio, Rafael (2018). La actual superioridad moral del victimismo. En DISIDENTIA. Recuperado del sitio de internet: https://disidentia.com/la-actual-superioridadmoral-del-victimismo/

Lenin (1973). El derecho de las naciones a la autodeterminación. Recuperado del sitio de internet: https://www.marxists.org/espanol/ lenin/obras/oe12/lenin-obrasescogidas05-12. pdf

\section{BIBLIOGRAFÍA COMPLEMENTARIA}

Anderson, B. (1993), Comunidades principales. Buenos Aires, Argentina: F.C.E.

Bauman, Z. (2007), Identidad, Buenos Aires, Argentina: Losada.

Billing, M. (1995), Banal Nacionalism, Londres, Inglaterra: SAGE.

Corcuera Atienza. J. (1979), Orígenes, ideología y organización del nacionalismo vasco (1876-1904), Madrid, España: Siglo XXI.

Druliolle, V. and Roddy Brett (2018), The Politics of Victimhood in Post-conflict Societies, London, Inglaterra: Palgrave Macmillan.

Erner, G. (2006), La société des victimes, París, Francia: La Découverte.

Gellner, E. (1988), Naciones y nacionalismo, Madrid, España: Alianza.

Gigliani, D. (2917), Crítica de la víctima, Barcelona, España: Herder.

Girard, R. (1972), La violence et le sacré. París, Francia: Grasset.

Hobsbawm, E. y Ranger, T. (edit.) (2002), $L a$ invención de la tradición, Barcelona, España: Crítica.

Horwitz, R.B. (2018), Politics as Victimhood, Victimhood as Politics. Journal of Policy History. Cambridge University Press. Volumen 30, Number 3. 
Hughes, H. (1994), La cultura de la queja. Barcelona, España: Anagrama.

Kautsky, K, (2000) La nacionalidad moderna, en, Cuadernos de pasado y presente, $\mathrm{n}^{\circ} .73$, México, México: siglo XXI

Kepel, G. (1984), La revancha de Dieu, París, Francia: Seuil.

Neveux, O. (2013), Politiques du spectateur, París, Francia: Editions La Découverte.

Nicolas, G. (1993). De l'usage des victimes dans les strategégies politiques. Cultures et Conflicts, $n^{\circ}$ 8. 1993.
Nietzsche, F. (1996) Genealogía de la moral, Madrid, España: Alianza.

Sánchez de la Torre, A. (1985), Sociología de las transformaciones jurídicas en la sociedad europea, Madrid, España: Instituto de Estudios Políticos.

Spencer, H. (2012), El hombre contra el Estado, Madrid, España: Unión Editorial. 